\author{
G U E S T E D I T O R I A L
}

\title{
Special Section on Storage, Processing, and Retrieval of Digital Media
}

\author{
Minerva M. Yeung \\ Intel Corporation \\ Microprocessor Research Laboratories \\ MS SC12-303 \\ 2200 Mission College Boulevard \\ Santa Clara, California 95052

\section{Chung-Sheng Li} \\ IBM Thomas J. Watson Research Center \\ 30 Saw Mill River Road \\ Hawthorne, New York 10532
}

\author{
Rainer Lienhart \\ Intel Corporation \\ MS SC12-303 \\ 2200 Mission College Boulevard \\ Santa Clara, California 95052

\section{Boon-Lock Yeo} \\ TeraCentral Corporation \\ 10181 Bubb Road \\ Cupertino, California 95014
}

Microcomputer Research Laboratory

Recent advances in computing and communications are leading to the creation of large-scale databases of visual and multimedia information. Such databases are finding ready applications in a wide range of fields such as advertising and marketing, education and training, entertainment, medicine, and remote sensing. Because of the very nature of visual and multimedia data, new and innovative methods are called for in modeling, processing, organizing, and indexing of this data for efficient storage, management, access, and delivery of the content. The goal of this special section is to highlight the new research areas and explore technology frontiers, by soliciting and selecting quality papers addressing issues from various aspects of storage, search, retrieval, and processing of digital media data (video/image/audio) and across a wide range of research disciplines.

For this special section, we have so- licited papers in relevant areas, ranging from content capture and processing, database management, new results on similarity measures and semantic features, and query methods to multimedia systems embracing leading-edge technology, and special applications of media management, retrieval, and processing across multiple fields, from consumer media systems, digital libraries, and media imaging to remote sensing. We encouraged the authors of some very promising papers in the SPIE/IS\&T Electronic Imaging Symposium (San Jose) 2001 Conference on Storage and Retrieval of Media Databases to submit a full journal-quality version of their conference manuscript to this special section. We also received submissions from outside of the conference, in response to our general call for papers. All submitted papers have undergone multiple peer-reviews, and we accepted 12 papers after two rounds of revisions and follow-up reviews.

We have classified the 12 papers into four major categories: (A) Contentbased Image Retrieval (the first two papers), (B) Content-based Video Retrieval (the next four papers), (C) Video Categorization and Summarization (the following three papers), and (D) Systems and Applications (the last three papers).

We would like to thank all those who have contributed significant time and effort to make this special section what it is today-the authors, JEI editor Jan Allebach, JEI staff members, and our reviewers, in addition to the efforts of the guest editors. This was a tremendous accomplishment given the tight deadlines we had to meet.

We hope you will enjoy the papers.

Special note from Minerva: many thanks to my fellow guest editors, 
Chung-Sheng, Rainer, and Boon-Lock, who helped to pull the papers and the issue together in such a short period of time!

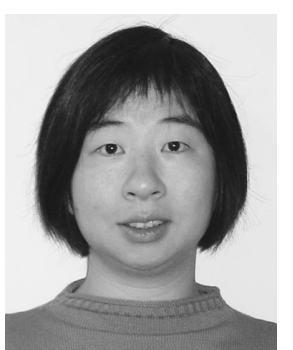

Minerva M. Yeung is a principal engineer with Intel Corporation and leads $R \& D$ of nextgeneration digital media and signal processing technology, computing models, and media architecture in the Microprocessor Research Labs. Her current research topics include ease-of-use of media technology, digital media delivery, protection, management, wireless communications, and computer architecture for media computing and communications. Prior to working at Intel, she was a research staff member with IBM T. J. Watson Research Center. She has published over 45 technical and invited papers and holds 6 U.S. patents with more than 10 pending applications in multimedia technology, information management systems, media processing, digital watermarking, pattern recognition, digital TV, etc. She and her work have been featured in the New York Times, IEEE Spectrum, Computer, EE Times, American Scientists and other magazines. She has served as an associate editor for IEEE Transactions on Multimedia and IEEE Signal Processing Letters, co-chaired the Wireless Multimedia Forum (an industrial forum with more than 40 member companies to define nextgeneration wireless media technology), and is the co-chair of the wireless communications session for the Frontiers of Engineering Symposium organized by NAE. She holds a PhD from Princeton University and a BSEE from Purdue University. She has been chairing the SPIE/IS\&T Electronic Imaging Symposium Conference on Storage and Retrieval of Media Databases since 1999.

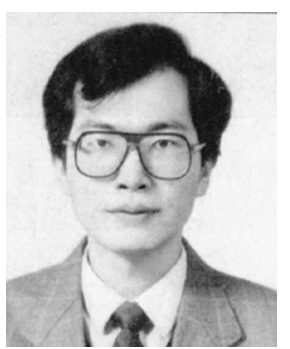

Chung-Sheng Li is currently with IBM T. J. Watson Research Center as senior manager for the E-commerce and Data Management Department. Previously, he managed the Image Information System Group (1996-1999) and Data
Management Department (1999-2000), and was a research staff member (1991-1996). He received his BSEE degree from National Taiwan University, in 1984, and the MS and $\mathrm{PhD}$ degrees in electrical engineering and computer science from the University of California, Berkeley, in 1989 and 1991, respectively. He is currently an associate editor for the IEEE Transactions on Multimedia and Journal of Computer Vision and Image Understanding, and the technical editor for the IEEE Communications Magazine. He has authored or coauthored more than 120 papers and received a best paper award from the IEEE ICCD in 1992. He has also received multiple awards from IBM for his technical achievements. His research interests include broadband and wireless applications, such as digital library, information and media marketplace, content-based retrieval of images and image sequence, knowledge discovery and data mining, content adaptation, and pervasive commerce. $\mathrm{He}$ is the principal investigator for NASAfunded digital library project and a DARPA bio-surveillance project at IBM. He has been a co-chair of the SPIE/IS\&T Electronic Imaging Symposium Conference on Storage and Retrieval of Media Databases since 2001.

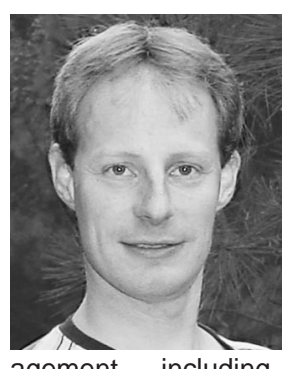

Rainer Lienhart is currently a staff researcher at Intel's Microcomputer Research Lab in Santa Clara working on video technologies beyond simple video encoding/decoding, multimedia management including object detection/ segmentation, image/video search, browsing and retrieval, and multimedia peer-topeer systems. He received the diploma in computer science and applied economics from the University of Mannheim, Germany, in 1994. In the same year he joined the Tenet Group at the International Computer Science Institute in Berkeley for six months and in 1997 he was a visiting researcher in the Visual Computing Lab of Professor Ramesh Jain. In 1998, he received the doctoral degree in computer science from the University of Mannheim, Germany, for his thesis on "Methods for Content Analysis, Indexing and Comparison of Digital Video Sequences." He was a core member of the Movie Content Analysis Project (MoCA). He has been a co-chair of the SPIE/IS\&T Electronic Imaging Symposium Conference on Storage and Retrieval of Media Databases since 2001.

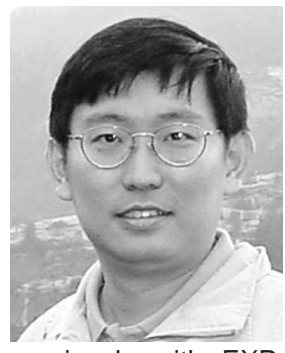

Boon-Lock Yeo is currently with TeraCentral Corporation, a startup technology company he co-founded in 2000 focusing on scalable and highperformance network storage systems. He was previously with EXP Systems as a vice president of technology and engineering in charge of building software technology platforms merging Internet and phone communications for enterprise value-added service. $\mathrm{He}$ worked at Intel Microprocessor Research Labs from 1998-1999 and shaped the research team building efforts and key project directions. From 1995-1997 he was a research staff member and later a manager with IBM T. J. Watson Research Center. He is internationally known for his work on multimedia processing, video technology, and data compression. He has published over 30 technical papers (including an IEEE Transactions on CSVT best paper award) and currently holds 13 patents. He was an associate editor for IEEE Transactions on Image Processing and has served on program committees of many international conferences in his areas of expertise. He received his $\mathrm{PhD}$ in $\mathrm{EE}$ from Princeton University, and a BSEE (with highest distinction) from Purdue University. He was a cochair of the SPIE/IS\&T Electronic Imaging Symposium Conference on Storage and Retrieval of Media Databases in 1999 and 2000. 